University of South Florida

DIGITAL COMMONS

Digital Commons @ University of

@ UNIVERSITY OF SOUTH FLORIDA

South Florida

\title{
Balancing Informed Evaluation with Efficiency: Applying Copyright and Licensing Evaluation to Reserves and Interlibrary Loan
}

\author{
LeEtta Schmidt \\ University of South Florida, Imschmidt@usf.edu
}

Follow this and additional works at: https://digitalcommons.usf.edu/tlib_facpub

Part of the Library and Information Science Commons

\section{Scholar Commons Citation}

Schmidt, LeEtta, "Balancing Informed Evaluation with Efficiency: Applying Copyright and Licensing Evaluation to Reserves and Interlibrary Loan" (2019). Tampa Library Faculty and Staff Publications. 14. https://digitalcommons.usf.edu/tlib_facpub/14

This Article is brought to you for free and open access by the Tampa Library at Digital Commons @ University of South Florida. It has been accepted for inclusion in Tampa Library Faculty and Staff Publications by an authorized administrator of Digital Commons @ University of South Florida. For more information, please contact digitalcommons@usf.edu. 
Running Head: BALANCING INFORMED EVALUATION WITH EFFICIENCY

Balancing Informed Evaluation with Efficiency: applying copyright and licensing evaluation to reserves and interlibrary loan

\author{
LeEtta Schmidt \\ Imschmidt@usf.edu \\ ORCiD: orcid.org/0000-0002-9567-9065 \\ Digital Scholarship Services, Tampa Library \\ University of South Florida \\ 4202 E Fowler Ave., LIB122 \\ Tampa, FL 33620
}

This is an Accepted Manuscript of an article published by Taylor \& Francis in the Journal of Access Services on 27 September 2019, available online:

https://doi.org/10.1080/15367967.2019.1659739 
Running Head: BALANCING INFORMED EVALUATION WITH EFFICIENCY

\begin{abstract}
This article examines steps taken at one academic library to address issues encountered when attempting to create a foundation of copyright knowledge to assist staff in reserves and interlibrary loan. It reviews the development of a copyright policy for the library that specifically addressed interlibrary loan and reserves activities. It also addresses how conducting staff instruction, developing process documentation, and having regular training meetings, enhanced each department's ability to incorporate the new policy into daily workflows. Finally, it points out new issues encountered when attempting to simplify how copyright and licensed materials are handled.
\end{abstract}

\title{
Keywords
}

Interlibrary loan, Reserves, Course Reserves, Copyright, Policy 
Running Head: BALANCING INFORMED EVALUATION WITH EFFICIENCY

\section{Balancing Informed Evaluation with Efficiency: applying copyright and licensing evaluation to reserves and interlibrary loan}

Library and Information Science literature reports on a growing demand upon librarians to provide guidance and education on copyright law and intellectual property issues (Hansen, Cross \& Edwards, 2013). Academic libraries are exploring the needs for copyright services in the library, as demanded by their patrons and their institutional administration. They are also exchanging information on what these services may look like, who they will serve, and how they will be delivered. Within this literature is a general call for libraries to position themselves as reliable resources for instruction and information on copyright. More specifically, staff who handle services like interlibrary loan (ILL) and reserves are encouraged to make a study of copyright law as it affects the services they provide (Hilyer, 2002; Hansen, Cross \& Edwards, 2013). There are many resources that could help library staff to accomplish this if given the time to study and the leeway to make their own judgement calls when handling their daily request loads. However, some articles tracing the launch of a pilot program or analyzing a service have concluded that individual request analysis and permissions seeking creates an unmanageable burden on library service staff. Yet, there is little guidance for libraries who need to balance high demand services with thoughtful copyright evaluation.

The University of South Florida Libraries was in need of this type of balance. The established ILL and reserves services had been through multiple changes in leadership, systems, and processes with little attention paid to how each department considered the usage of copyrighted material beyond the minimum evaluation provided by the request management systems. Each service adhered to short processing times to maintain and improve relationships with patrons who were heavy users of the services. The concept of devoting time to the study of copyright law or incorporating a complex analysis process into the daily workflow became an overwhelming prospect in light of these turnaround demands. This article will trace the steps taken so far at the University of South Florida Libraries to 
Running Head: BALANCING INFORMED EVALUATION WITH EFFICIENCY

balance the needs of ILL and reserves to meet extremely short processing expectations while, at the same time, handling copyrighted material in adherence to university policy and U.S. copyright law. It will outline these efforts from initial meetings of all parties to the creation of a library copyright policy and supporting process steps.

\section{Literature Review}

\section{Copyright and the library}

The literature is rich with foundational articles discussing how exceptions to copyright law and court cases affect a library's delivery of services. These articles serve to introduce libraries to potential copyright issues as well as provide a glimpse into how changes in copyright law have affected libraries in the last fifteen to twenty years. For example, Henry Carter's (2008) article on the Technology, Education and Copyright Harmonization (TEACH) Act takes a close look at why a change to copyright law aimed primarily at classroom educators will affect library services. Additionally, Tim Brooks (2012) article on a recent U.S. Copyright Office report on bringing pre 1972 audio recordings under federal law examined publisher concern and reluctance regarding the increasing prevalence of the digital use of copyrighted materials by library users.

This concern is not only related to the library's provision of their electronic collections but also to the library services that are more frequently providing material electronically, whether that material was electronic or print in origin. Dwayne Buttler (2012) commented, in his work examining how copyright limits restrict special collections and archives, that "copyright has quickly evolved from exerting a limited influence on some activities in academic libraries such as ILL and reserves, to affecting near all facets of increasingly digital libraries (p291)." This increased emphasis on copyright issues in providing library services, combined with patron demand for information on copyright, has made libraries a central point for providing instruction and reliable information on copyright. 
Running Head: BALANCING INFORMED EVALUATION WITH EFFICIENCY

\section{Interlibrary loan and reserves services}

A demand on libraries for copyright adherence, moderation, education, and information, naturally has become a challenge to the library employees responsible for delivering library services that have been specifically affected by copyright law. The long history of libraries searching for the most efficient way to develop services in adherence to copyright law can be easily seen in LIS literature where many older publications provide the most valuable insight. Lee Andrew Hilyer (2002) in chapter 8 of his primer on ILL, looked at how copyright law, specifically fair use, or Section 107, and the limitations on exclusive rights for reproductions by libraries and archives, Section 108, along with generally accepted guidelines for using copyrighted material, calls for all members of an ILL department to develop broad knowledge of copyright and related guidelines. Hilyer (2006) clarifies in a later article that in depth copyright knowledge is not the goal so much as complete knowledge of the fundamentals with emphasis on parts of the law and guidelines that affect ILL.

One of the prevailing guidelines in ILL, that of the Commission on New Technological Uses of Copyrighted Works (CONTU), restricts borrowing libraries to making five requests for copies from the last five years of any specific journal title before obtaining permission from the rights holder for additional copies. Rebecca Butler (2003) points out that this is a limit on how much may be borrowed, but not necessarily the format in which it is transmitted, whether it is print or electronic. Brice Austin (2004) in his work on looking at the history of electronic reserves and copyright, highlights publisher's concern over the threat presented to their profits by electronic delivery of library services. This concern naturally set the stage for publishers restricting possible uses of their content through the licenses on electronic journal and resource packages. Ultimately licensing restrictions would serve to hamper electronic resource sharing by adding layers of complications to copyright restrictions that already caused confusion with ILL practitioners. According to Cindy Kristof (2018), this over complication leads some ILL departments to refuse requests for electronic content all together. 
Running Head: BALANCING INFORMED EVALUATION WITH EFFICIENCY

Where interlibrary loan gets specific mention in copyright law through section 108 , and is specifically addressed in the CONTU guidelines, library reserves services do not. Austin's (2004) article goes on to point out how the 1976 copyright law failed to address reserves, and how attempts to apply various exceptions, like fair use (107), the exemption of certain performances and displays (110), and for reproduction by libraries and archives (108), generated more confusion than clarity. To fill the void, librarians in charge of reserves sometimes looked to the "Agreement on Guidelines for Classroom Copying in Not-For-Profit Educational Institutions with Respect to Books and Periodicals," which gave specific and restrictive descriptions on the amounts of material that may be copied from any one work for classroom use (Austin, 2004).

In an article on providing copyright compliant streaming audio reserves, Lisa Lazar and Carla Myers (2012) point out that the demand for electronic reserves services are just as prevalent, if not more so, than the demands encountered by ILL. Yet providing reserves electronically clashes with publisher concern that the ease of copying in a digital environment would lead students to make more copies of electronic files than they would of print counterparts (Austin \& Taylor, 2008). Even when acting in good faith, the lack of clarity on how copyright law governs the provision of electronic reserves services by libraries makes managing such a service inherently risky (Wang \& Baker, 2013).

Astrid Oliver (2008) has also pointed out, in her article on current practices in electronic reserves, that the lack of clarity on who holds the responsibility for copyright compliance is not clear or standardized. While some institutions have policies that set expectations regarding whether responsibility is held by the instructor or the library, this is not always the case. Regardless of a set institutional policy, libraries often find that the best way to ensure adherence to copyright law is to centrally handle the evaluation and permissions requesting within the reserves service (Bridgewater, 2008). This can also deepen the relationship between instructing faculty and library staff, as Rachel Bridgewater (2008) noted in her article about shifting the responsibility of obtaining permissions from 
Running Head: BALANCING INFORMED EVALUATION WITH EFFICIENCY

academic departments to the library. However, programs where the library takes the whole burden of permissions requesting, like those written about by Henry Carter (2008), and J. Christopher Holobar \& Andrew Marshall (2011), often result in the conclusion that the staff effort, time, and cost involved make the continuation of the service untenable. Donny Smith (2003) noted that library staff are put in reserves positions with little training and little time for learning Intellectual Property law amid other necessary development and training. The same can be said of many interlibrary loan department staff. This can compound the staff effort required and lead reserves services to limit the types or amounts of materials they offer beyond what copyright law requires (Cubbage, 2007).

\section{Policies and procedures}

In Donny Smith's (2003) article on copyright issues specific to electronic reserve, he discussed that among the questions reserves staff should consider when addressing a request is whether the institution has a copyright policy. However, these institutional level policies may not address specific library activities. This is likely the reason why library deans and directors have been called on to create library specific copyright polices meant to guide services like ILL and reserves (Eye, 2013). However, a library policy cannot stand alone, as Hansen, Cross and Edwards (2013) caution in their article analyzing the policy and practice of ARL libraries regarding electronic reserves. Policy should be established as an assistance to process to avoid the possibility that a less thorough rights analysis would under or overestimate "the true bounds for permissible use of copyrighted works." (p70). While there are several incisive articles available that explore the various exceptions within copyright law and guidelines adopted by higher education that guide library process and services, there is not much literature on how to bridge policy and day to day practice in ILL and reserves. This article will examine the steps taken by one library in creating a process to incorporate copyright policy and compliance into the daily demands ILL and reserves services.

\section{Background}


Running Head: BALANCING INFORMED EVALUATION WITH EFFICIENCY

The University of South Florida is a metropolitan public research university on the west coast of Florida. This article will focus on services provided by the USF Libraries at the Tampa campus, main library. Both ILL and reserves at the USF Libraries is high traffic, leanly staffed, and heavily automated. Both services have an exceptionally quick turn-around expectation that has been used in marketing the services and making them more attractive for new and continuing users. The two services are not located in the same department nor do they share a reporting structure. The Copyright Librarian position at the USF Libraries was established in 2015 to oversee both ILL and copyright instruction and services. In 2017, the position was moved and refocused under a different reporting structure and departmental affiliation from either ILL or reserves.

The services at USF Libraries were first put in place without the support of a copyright policy or process. This had created a situation where ILL and reserves staff functioned under highly simplistic and un-developed rules regarding the copyright evaluation of requested materials. Requests that resulted in more complex questions or that did not fit the prescribed rules were delayed or canceled. After the Libraries created a Copyright Librarian position 2015, the complex questions were sometimes, but not always, referred to the Copyright Librarian. This slowed down the delivery on requests and contributed to faculty dissatisfaction with the services and additional stress on staff. The involvement of the Copyright Librarian at this juncture served only to remove the request from the staff workflow. The librarian would often communicate directly with the faculty requester during problem solving, after which, she would relay a final decision to staff. These exchanges provided no training or learning opportunity for staff.

\section{Discussion}

\section{Training and Discussion Sessions}

The first step that the Copyright Librarian took to address this issue was to make several appointments with the staff of each department. The agendas for the meetings were spare, 
Running Head: BALANCING INFORMED EVALUATION WITH EFFICIENCY

concentrating on a few request issues or questions that had arisen prior to the meetings and providing training on copyright law and pertinent guidelines that had bearing on each question. This allowed time for the staff to come with their own questions, examples of request issues, and discussion. Revisiting issues that had been resolved earlier with the assistance of the Copyright Librarian gave the opportunity to discuss why requests were either processed or cancelled due to their copyright issues, and encourage staff in their own understanding of the situations. While basing copyright training on real life examples from recent work helped to make the training immensely relevant. Meetings between the Copyright Librarian and the staff of both ILL and reserves also allowed staff to explain the stresses and pressures they experienced when processing requests and encountering issues they did not feel confident in addressing.

During the meetings it became clear that the staff felt unsupported by established policy and processes. Even with a greater understanding of how copyright law applied to their daily work, staff communicated the concern that they alone would not have the authority answer faculty questions regarding copyright issues in requests for materials. The questions and issues that staff regularly encountered were not addressed by the existing university copyright policy or any written process documents. When problem solving as needed, alone or with the help of their supervisor or the Copyright Librarian, staff often received push back from faculty patrons for whom they served as the primary communication point. Without a policy that explicitly supported decisions on the handling of copyrighted material in the services, faculty patrons could perceive the decisions as arbitrary. ILL and reserves services staff felt as though they had no way to argue this point. Additionally, an evaluation of copyright on incoming requests needed to fit within the existing processes and systems in place. Both ILL and reserves used request management systems originally created by Atlas Systems, ILLiad and Ares respectively, to process incoming requests for material. 
Running Head: BALANCING INFORMED EVALUATION WITH EFFICIENCY

ILLiad, the request management system for ILL, included a copyright queue where article requests from local patrons were automatically sorted for evaluation in line with CONTU guidelines. Each incoming request labeled as either an article or book chapter was first checked for publication year by the system and then put in a queue that compared its title and year to other requests for similar material, indicating to staff which titles had been requested over five times. The evaluation of this queue was required before moving the request on to any further step in the fulfillment process. The placement of this queue in the request process, and its construction around CONTU, made the bulk of evaluating requests simple for ILL staff.

The reserves service utilized the Ares system for their request management. Ares included a process where article and book chapter requests were automatically flagged for copyright evaluation based on journal/book title, year, and other identifying information. Unlike ILLiad's copyright queue, the flagged requests in Ares could move through several processing steps before copyright was evaluated, which allowed staff to address copyright when they had time instead of at the start of each request. In addition to the system provided queues, each service needed a clear understanding and manageable evaluation process for addressing questions of copyright on incoming requests within their own established workflows.

A final aim of the meetings was to establish a pathway for staff working in the ILL and reserves units to gain assistance from the Copyright Librarian when they needed it. Though there was no official barrier in place between the departments, there was observed reticence to involving the Copyright Librarian in departmental activities. While acknowledging the need for balance when dealing with the high turnaround demands of the department, and the other responsibilities of the Copyright Librarian, establishing an open channel of communication was necessary to address future issues and possible training opportunities.

\section{Developing a Policy}


Running Head: BALANCING INFORMED EVALUATION WITH EFFICIENCY

In order to address the lack of official documentation that ILL and reserves staff could rely upon when communicating with patrons, the Copyright Librarian employed an existing discussion group devoted to library copyright issues, called the Copyright Team, to help ascertain where a library policy could provide needed additional structure and guidance not covered within university policy. It was important to avoid rewriting material established in other policy documents and U.S. Copyright Law, or indicate that the Libraries accepted blame for patron use of materials provided by library services. Instead, the policy would establish adherence to these pre-existing documents or rules. Additional statements in the policy would indicate if the library adhered to any established best practices or guidelines and give information how the library intended to responsibly use copyrighted material in any of several situations.

Though not specifically indicated in either university or library policy, the statements of adherence to exceptions in US Copyright law and best practices were constructed in deference to USF as a non-profit institution and the Libraries being open to the public. Beyond University policy and U.S. Copyright Law, the Copyright Team looked to the posted policies in peer and aspirant institution libraries. Library activities that did not need any specific elaboration on how they adhered to university policy or copyright law were not included. For example, the activities of the Institutional Repository were determined to be covered by the overall statement that the Libraries' would adhere to University Policy and U.S. Copyright law. In addition to the overall statement of adherence to university policy and copyright, the Libraries' policy specifically addressed the following areas (USF Libraries, 2018):

Information and guidance. Informed by statements in peer and aspirant institutions, the Copyright Team deemed it important to establish that the instruction and educational support the Libraries' offered concerning copyright and related intellectual property issues was not legal advice. This would be true whether the incumbent of the Copyright Librarian position had earned a Juris Doctorate or not. 
Running Head: BALANCING INFORMED EVALUATION WITH EFFICIENCY

Unmediated copying. Unmediated copying was included in library policy as a rare case of partial reiteration of university policy. Though university policy established that the Libraries may provide unsupervised reproducing equipment, the Copyright Team viewed this as an important opportunity to reinforce the patron's own responsibility in using copyrighted material within the library.

Access to collections. The statement on access to collections incorporated allowed library processes established in university policy: that of making copies for private study, research, and scholarship. It also made clear that any fees charged for providing such copies, either to libraries making an interlibrary loan request to borrow USF materials or to patrons making a document supply request, would be for cost recovery only and not represent any profit generating activity. This inclusion was informed by the study of peer and aspirant institutions as well as Section 108(a) of US Copyright law which establishes that certain reproductions made of copyrighted material by libraries are not infringements if "(1) the reproduction or distribution is made without any purpose of direct or indirect commercial advantage" (U.S. Copyright Office, 2011, p.19).

The statement also reflects expectations established in the Libraries' contracts with database and content providers. It clarifies that remote use is restricted to authorized users only, and it establishes the patrons' accountability in ensuring their use of database content is scholarly, research oriented, and non-commercial as required by the licensing agreements.

Reserves. The reserves section of the policy was carefully constructed to elaborate on university policy and establish clearly to what best practices the Libraries adhered. This section of the policy would support reserves personnel when explaining processes built upon the policy. As Austin (2004) noted in his article addressing exceptions to copyright law and guidelines to using copyrighted materials in library services, the 1976 copyright law failed to address reserves specifically. USF Libraries were no different to the other libraries that Austin referenced, and had historically attempted to apply various exceptions including fair use (Section 107), the exemption of certain performances and displays 
Running Head: BALANCING INFORMED EVALUATION WITH EFFICIENCY

(Section 110), and for reproduction by libraries and archives (Section 108), to the provision of reserves services. Failing this, the "Agreement on Guidelines for Classroom Copying..." were often turned to for guidance. This resulted in staff confusion and sometimes contradictory instruction to faculty using reserves services. Upon examining the many different types of requests that reserves received, a series of initial questions rose to the surface that informed the statement of policy regarding reserves services.

First, Section 108(d) (2) of US Copyright law requires that libraries accepting requests for reproductions from a library user directly or via another library to display "prominently, at the place where orders are accepted ... a warning of copyright." This most directly applies to interlibrary loan and document delivery services. While the same section in US Copyright law could not comfortably be applied to reserves, including a similar warning on reserves web pages and as a companion to any material provided by the reserves service harmonized the delivery of what the library considered similar services.

Reserves serves primarily as a support for faculty using material in their classes. Faculty making use of the exceptions outlined in Section 110 of US Copyright law, are allowed to make certain uses of works in classroom situations if the copy was lawfully made. Adding this legal copy stipulation to the library policy helped to provide educational guidance to any faculty request in which this the legal state of the material requested was unclear. Though access restrictions are also given a treatment in Section 110 , the policy statement on restricting access to electronically reserves clarified how the Libraries intended to provide the service and what requirements the Libraries made of request management systems they employed for service delivery.

A statement on directly linking to material available in electronic resources, when available, instead of supplying any type of digital copy, directly referenced license language common among the many content providers with which the library contracted. Finally, reserves services would only accept 
Running Head: BALANCING INFORMED EVALUATION WITH EFFICIENCY

and fulfill requests that complied with university policy, which clearly indicated that the Libraries retained the right to refuse or remove material based on law-related or administrative concerns.

Interlibrary loan. As mentioned above, providing a notice of copyright on interlibrary loan web pages is a requirement of Section 108(d)(2) of US Copyright law. The remaining statements regarding the provision of interlibrary loan services directly reference the CONTU Guidelines: that of evaluating for compliance and retaining records for three years (Final Report of the National Commission on New Technology Uses of Copyrighted Works (CONTU), 2003). Though not included in US Copyright law and not specifically given any treatment in university policy, the CONTU Guidelines provide a generally accepted best practice in the resource sharing community. The request management system employed by ILL, ILLiad, also made automated checks on incoming requests based on the CONTU Guidelines. The statements within the policy on evaluation based on CONTU, however, were written to ensure that the Libraries would not be restricted from making evaluations, or decisions on requests, based simply on University Policy or Copyright law.

Preservation and Digitization. Also addressed in Section 108 of Copyright law, is how libraries can make reproductions of material for items that were damaged, lost, stolen, or deteriorating. In addition to the text of Section 108, Video At Risk (2012) was used to provide a structure in policy that would support a companion process for preservation of media. Specifically, the statement made in the policy addressed the Libraries' adherence to documenting the evaluation and replacement process if a copy was made to replace media that was damaged, deteriorating, lost or stolen.

Special Collections. Finally, the library policy formalized instruction that Special Collections had been providing to their users via departmental web pages. Though the statements made for special collections regarding furnishing a reproduction for private study reiterated those in USF Policy and elsewhere in the Libraries' policy, the unique flow and characteristics of Special Collections user group made it necessary to establish this separate section in the Libraries' policy. 
Running Head: BALANCING INFORMED EVALUATION WITH EFFICIENCY

\section{Incorporating the policy}

Discussions on the draft copyright policy became part of continuing meetings with the staff of the reserves and ILL departments. Additionally, services staff and the Copyright Librarian looked at how existing process documentation addressed or failed to address the utilization of system checks for copyright. Staff knowledge of their workflow steps and the systems they used every day were integral to the creation of process documents that both supported and relied on the Libraries' new copyright policy as well as outlined how copyright evaluation was incorporated into request processing.

The ILLiad copyright queue, constructed around CONTU guidelines, gave ILL staff a simple rule to follow when addressing the bulk of their requests. Individual patron requests in excess of the guidelines, e.g. requests for scans of all the articles or chapters from one volume or book, would be filled with a request of loan of the material that patrons would be expected to return as any other ILL loan. A description of what was happening in the queue, and why, was added to the in house staff manual to help ILL staff understand what was happening and remind them to look out for multiple requests from one patron that may be better processed as an individual loan request. An additional manual page was created to outline the process of creating a copyright report based on items processed in excess of CONTU, for which fees would need to be paid. Discussions between staff and the Copyright Librarian had highlighted that this process was also not well understood, and done on a varying schedule. Adding a step by step breakdown of the process along with reminders why it happened, would ensure that it could be completed by multiple people in the department. The Copyright Librarian and ILL staff also settled on a more regular schedule when the copyright report would be run.

Since the copyright queue was a flagged queue in Ares, meaning that requests could be filled and material provided before copyright was evaluated, it was also important to establish a regular schedule for this part of reserves processing. Similar to the documentation added to the ILL staff manual, step by step instructions were accompanied by short reminders why requests moved the way they did. The 
Running Head: BALANCING INFORMED EVALUATION WITH EFFICIENCY

copyright processing queue in Ares required more dedicated concentration from reserves staff since it was not based on any helpful guideline like ILL's CONTU. To address this, the Copyright Librarian and reserves staff came up with a list of questions to begin evaluation on requests, including:

1. Is the request live or has it been cancelled?

2. Is the request for a monograph or other whole item, i.e. not a copy or scan?

3. Does the library own or have access to the material electronically?

4. Is the request for linked content?

These questions helped reserves staff eliminate a variety of requests from copyright processing before needing to enter into any more in depth fair use evaluation or conversation with the requesting faculty. The first question, whether the request had since been cancelled, was important because requests would stay in the copyright processing flagged queue in Ares no matter what their delivery status. Copyright evaluation would not be necessary if faculty had cancelled a request before the material was provided. Similarly, copyright evaluation was not required for materials, like whole books and videos, which were put on physical reserves. Why these materials were identified by the system as needing copyright processing was not evaluated.

The majority of the Libraries' electronic databases and subscriptions were negotiated to allow for the use in electronic reserves provided to a restricted course management platform. Some of the licenses requested that the material be linked instead of uploaded into reserves. Question number three reminded reserves staff that, if the requested material could be found in the USF Libraries' electronic content, then filling the request with a link to the material did not need copyright evaluation. Similarly, if the material requested by the faculty consisted of a link to openly accessible internet content elsewhere, copyright evaluation in the reserves system would not be needed. University policy encouraged faculty to avoid making a copy, electronic or otherwise, if they could simply refer to existing 
Running Head: BALANCING INFORMED EVALUATION WITH EFFICIENCY

material by sharing a link. These four initial questions helped to drastically reduce the amount of concerted evaluation required by reserves staff by moving on a majority of the requests.

An email workflow was developed for the few reserves requests that were not eliminated by these first four questions, and which seemed to exceed the limits suggested to faculty by University policy (University of South Florida, 2013). Reserves staff would initiate contact with the requesting faculty via an Ares system email with an explanation, an offer to discuss the situation, and list of options including: substituting the content, arranging to pay for permissions, or removing the content.

After launching the policy, meetings between the staff of reserves, ILL, and the Copyright Librarian assessed the added processes and updated documentation in staff manuals and training materials. An attempt to incorporate easy to remember rules in both process documentation and instruction to patrons ran into obstacles. For example, it had become habit to assume that all the collections discoverable through the library were negotiated for the use by faculty in classes, and that any material found in the library collections could be easily linked by the faculty member to their online course in Canvas, the course management system used by the university. This was proved untrue when a statewide negotiated resource restricted the use of permalinks from within the catalog in order to control how the material was used, specifically disallowing its incorporation into Canvas course shells.

Similarly, the library was entertaining the idea of supporting resources that were purchased only for the use of one department which would also not allow permalinking to content. The Libraries did not have an electronic resource management system that made easy retrieval of license stipulations available to the staff of reserves and ILL, so these slight variations only added confusion in the midst of our attempts to create a clear structure for service delivery. Reserves staff had to make note of these few variances to remind themselves when encountered with a request for material that was contained within these specific collections. Likewise, instructions to faculty about using library content in their courses had to be delivered with a caveat. It became clear that the Libraries' policy and the process 
Running Head: BALANCING INFORMED EVALUATION WITH EFFICIENCY

documents for ILL and reserves could not address all request issues, though they were designed to address as many as possible. Requests for which the staff of either service felt unsure, would still be sent to the Copyright Librarian for evaluation and possible intervention.

\section{Conclusion}

The solution to providing some balance between the turn-around expectations of ILL and reserves services with the thoughtful evaluation of copyright on incoming requests, included the creation of a library policy and new process documentation. The project incorporated knowledge of database and subscription licenses, university policy, law, and best practice documentation, as well as understanding of the demands placed on different library service points, and the request management systems that each service used. The creation of a library policy and addition of process documentation that incorporated copyright evaluation into the workflows of both ILL and reserves, successfully addressed the majority of questions and concerns raised by ILL and reserves staff during initial meetings with the Copyright Librarian. The meetings between the Copyright Librarian and the staff of ILL and reserves helped to establish familiarity and a clear route of communication for problem solving. During the development of a library policy and clear process documents, seemingly new obstacles were uncovered, like an unforeseen variation in database agreements. Though adding complexity to processing, these new obstacles were rare and easily addressed by the improved communication methods developed by the Copyright Librarian and services staff during their meetings.

Embarking on the creation or review of a library policy that addresses the handling of copyrighted materials, especially in reference to library services like ILL and reserve, benefits immensely from the involvement of the staff of those departments. Almost constant communication, training and troubleshooting is necessary to find a balance between thorough evaluation of requests for copyright adherence and timely request processing and delivery. Staff input on processes and system constraints must be considered, whether copyright guidance is delivered via positions in charge of supervising ILL 
and reserves, or from an expert in another library department. Through continuous discussion with staff involved in providing the services, clear roads can be mapped from copyright policy to the executed processes of each service.

\section{References}

Austin, B. (2004). Reserves, electronic reserves, and copyright : the past and the future. Binghamton, N.Y. : Haworth Information Press, c2004. Co-published simultaneously as Journal of interlibrary loan, document delivery \& electronic reserve, volume 15, number 2, 2004. Retrieved from https://www.taylorfrancis.com/books/9781136435560

Austin, B. \& Taylor, K. (2008). Reserves, Electronic Reserves and Student Copying Practices at the University of Colorado, Boulder. Journal of Interlibrary Loan, Document Delivery \& Electronic Reserve, 18(1), 17-32, DOI: 10.1300/J474v18n01 04

Bridgewater, R. (2008). Shifting Responsibility for Electronic Reserves Copyright Permissions from the Academic Departments to the Library: From Confusion to Cooperation. Journal of Interlibrary Loan, Document Delivery \& Electronic Reserves, 18(2), 141-152.

https://doi.org/10.1300/10723030802098840

Brooks, T. (2012). Copyright \& Fair Use. ARSC Journal, 43(1), 77-82.

Butler, R. (2003). Copyright Law and Organizing the Internet. Library Trends. 52(2): 307317. http://hdl.handle.net/2142/8524

Buttler, D. K. (2012). Intimacy Gone Awry: Copyright and Special Collections. Journal of Library Administration, 52(3-4), 279-293. https://doi.org/10.1080/01930826.2012.684506

Carter, H. (2007). Copyright, Permissions and Fair Use in Interlibrary Loan and Electronic Reserve: Introduction. Journal of Interlibrary Loan, Document Delivery, \& Electronic Reserve, 18(1), 1. https://doi.org/10.1300/J474v18n01 01

Carter, H. (2008). Why the Technology, Education and Copyright Harmonization Act Matters to Librarians. Journal of Interlibrary Loan, Document Delivery \& Electronic Reserve, 18(1), 49-56. DOI: $\underline{10.1300 / J 474 v 18 \mathrm{n} 0106}$

Final Report of the National Commission on New Technology Uses of Copyrighted Works (CONTU). (2003). Retrieved from http://digital-law-online.info/CONTU/

Cubbage, C. (2007). The Changing Cost Environment of Managing Copyright for Electronic Reserves. Journal of Interlibrary Loan, Document Delivery \& Electronic Reserves, 18(1), 57-66.

https://doi.org/10.1300/J474v18n01 07 
Eye, J. (2013). Knowledge Level of Library Deans and Directors in Copyright Law. Journal of Librarianship \& Scholarly Communication, 2(1), 1-14. http://doi.org/10.7710/2162-3309.1103

Hansen, D., Cross, W., \& Edwards, P. (2013). Copyright Policy and Practice in Electronic Reserves among ARL Libraries. College \& Research Libraries, 74(1), 69-84. https://doi.org/10.5860/crl-313

Hilyer, L. A. (2002). Chapter 8: Copyright Considerations for the Inter library Loan Department. Journal of Interlibrary Loan, Document Delivery \& Information Supply, 13(1/2), 41-53. Retrieved from https://doi.org/10.1300/J110v13n01 10

Hilyer, L. A. (2006). Chapter 5: Copyright in the Interlibrary Loan Department. Journal of Interlibrary Loan, Document Delivery \& Electronic Reserves, 16(1/2), 53-64. https://doi.org/10.1300/J474v16n01 05

Holobar, J. C. \& Marshall, A. (2011). E-Reserves Permissions and the Copyright Clearance Center: Process, Efficiency, and Cost. Portal: Libraries and the Academy, 11(1), 517-531. Retrieved December 19, 2018, from Project MUSE database: https://muse.jhu.edu/article/409891

Kristof, C. (2018). The Development of Resource Sharing, Scholarly Communication, and the Role of Publishers in the Context of Academic Libraries. Library Trends, 67(2),

394. https://doi.org/10.1353/lib.2018.0043

Lazar, L. A., \& Myers, C. (2012). Desire to Listen: One Learning Management System-Based Solution to Providing Copyright Compliant Streaming Audio Reserves. Music Reference Services Quarterly, 15(3), 149-172. http://doi.org/10.1080/10588167.2012.700836

Oliver, A. (2008). Current Practices and Philosophy on Electronic Reserves, Course Management Systems, and Copyright Compliance: A Survey of the Council of Public Liberal Arts Colleges Libraries. Journal of Interlibrary Loan, Document Delivery \& Electronic Reserve, 18(4), 425437. https://doi.org/10.1080/10723030802181711

Smith, D. (2003). A Copyright Primer for Electronic Reserve: Copyright for Harried Electronic Reserves Staff. Journal of Interlibrary Loan, Document Delivery \& Information Supply, 13(4), 7990. https://doi.org/10.1300/J110v13n04 07

University of South Florida (2013) Copyrighted Materials - Use and General Principles Policy. http://regulationspolicies.usf.edu/policies-and-procedures/pdfs/policy-0-105.pdf

U.S. Copyright Office. (2011). Copyright Law of the United States and Related Laws Contained in Title 17 of the United States Code circular 92. Retrieved from: http://www.copyright.gov/title17/circ92.pdf

USF Libraries (2018) Copyright Policy. https://www.lib.usf.edu/library-administration/wpcontent/uploads/sites/17/2018/08/Copyright.pdf

Video at Risk (2012) Copyright Guidelines. VIDEO AT RISK: Strategies for Preserving Commercial Video Collections in Research Libraries. https://guides.nyu.edu/ld.php?content id=24818036 
Running Head: BALANCING INFORMED EVALUATION WITH EFFICIENCY

Wang, Y.-H., \& Baker, M. (2013). Effectively Managing Copyright Clearance: Electronic Reserves in a Large Distance Education University. Journal of Library and Information Services in Distance Learning, 7(1-2), 210-219. https://doi.org/10.1080/1533290X.2012.705658 